УДК 81.22

ББК 81

DOI: https://doi.org/10.17308/lic.2021.4/3810

\title{
НАЗВАНИЯ ТИПОВ ЗАВЕДЕНИЙ ОБЩЕСТВЕННОГО ПИТАНИЯ: ЛИНГВОСЕМИОТИЧЕСКИЙ АСПЕКТ
}

\author{
Л. В. Рыбакова \\ Сочинский институт (филиал) Российского университета дружбы народов \\ К. П. Иванова \\ Сочинский государственный университет
}

\section{NAMES OF TYPES OF EATING ESTABLISHMENTS: LINGUO-SEMIOTIC ASPECT}

\author{
L. V. Rybakova \\ Sochi Institute (branch) of the Peoples' Friendship University of Russia \\ K. P. Ivanova \\ Sochi State University
}

\begin{abstract}
Аннотация: в настоямее время происходят значительные изменения в терминологии, используемой для обозначения типов заведений общественного питания (3ОП). Однако лингвистических исследований названий типов ЗОП крайне недостаточно. Предметом изучения в данной статье является лингвосемиотическая система «названия типов ЗОП» как структурный элемент вывески ЗОП в курортном городе (Имеретинский курорт, г. Сочи). Целью исследования является выявление языковой и смысловой динамики в указанной системе как лингвокультурном коде, обеспечивающем проиессы кодирования и декодирования информации вывески. В работе использованы методы семиотического и лингвистического анализа. На первом этапе разработана теоретическая базовая модель лингвосемиотической системы «названия типов ЗОП», в которой общепринятые значения традиционных названий ЗОП представлены в виде системы парных дифференцирующих признаков. На втором этапе проведен лингвосемиотический анализ практического материала, начеленный на выявление отклонений от базовой модели. В результате выявлены и систематизированы признаки формирования нового лингвокультурного кода, проявляющиеся как на уровне смысловой структуры (культурных кодов), так и на уровне языкового кода. Построень 5 действующих моделей нетипичных способов репрезентации значения «тип ЗОП» в рамках вывески. Выявлены 2 новых по сравнению с базовой моделью значения, актуализирующиеся в смысловой структуре новых названий типов ЗОП. Сделаны выводы о тесной связи смысловой и языковой динамики в системе названий ЗОП с современными тенденциями в культуре питания. Намечены перспективные направления дальнейших исследований. Материаль статьи могут внести вклад в разработку методики лингвосемиотического анализа, а также быть применены в области маркетинга и создания привлекательного имиджа курортного города.

Ключевые слова: заведения общественного питания, вывески ресторанов, лингвокультурный код, культурный код, лингвосемиотический анализ, рекламный дискурс, культура питания.
\end{abstract}

Abstract: significant changes are currently taking place in the terminology used to designate types of eating establishments (EE). However, linguistic studies of the names of types of EE are extremely scarce. The subject of this article is linguo-semiotic system "names of EE types" as a structural element of the restaurant signage in a resort town (Imeretinsky resort, Sochi). The objective of the study is to identify linguistic and semantic dynamics

(C) Рыбакова Л. В., Иванова К. П., 2021

Контент доступен под лицензией Creative Commons Attribution 4.0 License.

The content is available under Creative Commons Attribution 4.0 License. 
in the specified system as a linguocultural code that provides the processes of encoding and decoding signage information. Methods of semiotic and linguistic analysis were used in the work. At the first stage, a theoretical Basic Model of the linguo-semiotic system "names of EE types" was developed. The Basic Model presents the generally accepted meanings of traditional EE names as a system of paired differentiating features. At the second stage, a semiotic and linguistic analysis of practical material was carried out, aimed at identifying deviations from the basic model. As a result, we identified and systematized features of the formation of a new linguocultural code, manifested both at the level of the semantic structure (cultural codes) and at the level of the language code. Five Operating Models of nontypical ways of representing the meaning "type of EE" in a signage were built. There were identified 2 new, in comparison with the Basic Model, meanings which are being actualized in the semantic structure of new names of EE types. Conclusions were drawn about the connection of semantic and linguistic dynamics in the system of names of EE types with modern trends in eating culture. Promising directions for further research were outlined. The materials of the article can contribute to the development of the method of linguo-semiotic analysis and can also be applied in the field of marketing and creating an attractive image of a resort town.

Key words: eating establishments, restaurant signage, linguocultural code, cultural code, linguo-semiotic analysis, advertising discourse, eating culture.

\section{Введение}

Наш интерес к данной теме возник в процессе более масштабной работы по изучению вывесок заведений общественного питания (далее - 3ОП) как текста массовой коммуникации, функционирующего на стыке двух лингвосемиотических систем: коммуникативного пространства города (на примере курортного города) и ресторанного дискурса.

В процессе анализа выяснилось, что парадигма названий типов ЗОП заслуживает особого внимания не только с точки зрения ее роли в тексте вывески, но и как самостоятельный объект исследования.

Приведем краткий обзор разноплановых исследований, указывающих на актуальность данной темы.

В последние годы происходят значительные изменения в системе ЗОП, связанные с новыми тенденциями в культуре питания. Соответственно, наблюдается значительное увеличение количества терминов, употребляющихся для обозначения типов ЗОП. Так, в исследовании особенностей номинации ЗОП Москвы приводятся 45 частотных наименований [1], в то время как официальная классификация ГОСТ [2] содержит только 8 типов. Пожалуй, упомянутое выше исследование - это единственная известная авторам работа, в которой анализируются структурно-семантические особенности собственно названий типов ЗОП. В подавляющем же большинстве лингвистических исследований основное внимание уделяется коммерческим названиям ЗОП (неймам), которые изучаются с точки зрения их роли в создании привлекательного образа ЗОП, например [3], и имиджа отдельных городов, например [4]. Названия типов ЗОП затрагиваются в ряде исследований вывески как текста рекламного жанра. Но при этом авторы также в основном фокусируются на коммерческом названии как элементе, имеющем наибольшую смысловую нагрузку в структуре вывески [5].
На наш взгляд, смысловая структура названий типов ЗОП обладает не менее сильным рекламным потенциалом. Если нейм повышает привлекательность заведения в плане выбора между однотипными заведениями, то сам выбор ЗОП потенциальным посетителем зависит от типа заведения, так как именно тип наиболее тесно связан с характером потребностей потенциального клиента (перекусить или полноценно поесть, просто поесть или поесть и приятно провести время и т. п.).

В связи с изучением смысловой составляющей названий типов ЗОП следует отметить отдельные работы в области культурологии. Так, Н. А. Колосова исследует историческую динамику восприятия пространства ресторана в культуре русского города [6]. А. В. Смирнов анализирует отдельные новые форматы ЗОП как источник формирования новых культурных смыслов [7]. Оба исследования указывают на тесную связь отдельных типов ЗОП с социально-культурными особенностями современности.

Отметим также, что А. В. Олянич, описывая когнитивную систему глюттонии, указывает, что в среде общественного питания происходит формирование «выработанных человечеством культурных ценностей в области потребления еды» [8, с. 12]. Но при детальной изученности ряда знаковых подсистем глюттонии система «названия типов ЗОП» пока остается в стороне.

Целью представленного исследования является выявление языковой и смысловой динамики в знаковой системе «названия типов ЗОП» как лингвокультурном коде, который обеспечивает процессы кодирования и декодирования информации, содержащейся в вывеске ЗОП.

Наше понимание сути и коммуникативных функций лингвокультурного кода опирается на концепции Р. Барта и В. М. Савицкого. Вслед за Р. Бартом под культурным кодом мы понимаем сумму обществен- 
ных представлений и мнений, культурного опыта, транслируемого функционирующими в обществе текстами [9]. Как любой код, лингвокультурный код представляет собой «сверхтекстовую организацию значений» [там же, с. 454], возникающую в процессе вербализации культурного кода [10]. Система лингвокультурных кодов лежит в основе структурирования и осмысления явлений окружающего мира (моделирующая функция), влияет на поведение и принятие решений (регулирующая функция), а носители языка мыслят в категориях лингвокультурного кода «и на этой основе формируют и вербально формулируют мысль» [там же, с. 58] (речепорождающая функция).

Для достижения цели были поставлены следующие задачи:

- разработать теоретическую базовую модель лингвосемиотической системы «названия типов ЗОП», отражающую смысловую структуру традиционных названий ЗОП;

- выявить и систематизировать отклонения от базовой модели и способы лингвистической репрезентации новых значений на примере вывесок ЗОП туристической зоны Имеретинского курорта (г. Сочи).

Авторы надеются, что результаты исследования могут быть полезны научному сообществу, занимающемуся изучением рекламно-информационной функции вывески, а также специалистам в области маркетинга и создания привлекательного образа города.

\section{Материал и методы исследования}

Место сбора материала - Имеретинский курорт (г. Сочи), получивший в декабре 2020 г. статус первой в России федеральной территории Сириус, - является самым молодым в России и активно развивающимся туристическим центром. Это уникальное место соединения традиционных представлений о г. Сочи как всероссийской здравнице и современных тенденций в области туризма.

Не менее уникально это место и как источник практического материала, так как здесь взаимодействуют региональная специфика и общекультурные тренды.

Материалом исследования послужили вывески ЗОП первой и второй линии прибрежной полосы (порядка 7 км), отобранные методом сплошной выборки в процессе непосредственного физического наблюдения и фотографирования (объем выборки 152 точки, функционировавшие на момент завершения сбора и обработки данных - март 2021 г.). Вместе первая и вторая линии являются туристической зоной (и местом отдыха местных жителей) и характеризуются очень большой концентрацией ЗОП. Таким образом, данная территория представляет собой образец реализации идеи зонирования курортного го- рода в рамках стратегии «main-street», которая еще недавно обсуждалась как перспективное направление развития туристского пространства г. Сочи [11].

Специфика локализации материала обусловила практическую значимость нашего исследования. Это первое из известных авторам лингвистическое исследование представленного практического материала.

В работе использованы методы семиотики (синтагматический, парадигматический, интерпретационный, оппозиционный анализ) и лингвистики (семантический, дефиниционный, контекстуальный анализ). В процессе исследовании мы опирались на алгоритм семиотического анализа, описанный Д. Чандлером в [12].

Исследование проводилось в два этапа. На первом, подготовительном, этапе были разработаны структурная схема вывески 30 К как базового текста исследования и теоретическая базовая модель лингвосемиотической системы «названия типов 30П», послужившие основой для анализа практического материала. Описание этих инструментов исследования мы дадим ниже. На втором этапе был проведен лингвосемиотический анализ системы названий типов 3ОП как парадигмы синтагматического пространства вывески на материале нашей выборки. Анализ смысловой структуры указанной парадигмы проводился с привлечением материалов интернет-источников: публикаций гастрономической направленности на специализированных сайтах (restoranoff.ru, marketmedia.ru и др.), а также описаний заведений рестораторами и отзывов посетителей на информационно-рекламных сайтах (azur.ru/veseloe/ rest, tripadvisor.ru, otzovik.com).

В рамках структурной схемы вывеска $3 О П$ рассматривается нами как знаковая система, представляющая собой комбинацию взаимодействующих вербальных и невербальных знаков, образующих вместе единое визуальное и функционально-смысловое целое. В синтагматическом пространстве вывески мы выделили три вербально выраженных структурных элемента: 1) название типа заведения; 2) собственное название заведения - коммерческое имя, нейм; 3) дополнительная информация. Каждый элемент представляет собой самостоятельную знаковую подсистему - парадигму значений. В рассматриваемой нами парадигме «название типа 3ОП» актуализируется индексальная функция вывески - указание на ЗОП, а также информационно-рекламная функция, связанная со смысловой структурой лингвистических знаков указанной парадигмы.

Базовая модель лингвосемиотической системы «названия типов 30П» построена с целью выявления изменений, происходящих в настоящее время в данной системе путем сравнения с некими общепринятыми образцами. Это теоретическая, абстрагиро- 
ванная от конкретных текстовых образцов модель знаковой системы как лингвокультурного кода.

Базовая модель включает систему общеизвестных названий типов ЗОП (языковой код) и систему значений, ассоциируемых в массовом сознании с этими названиями (культурный код). К общеизвестным мы отнесли названия типов 3ОП, включенные в толковые словари (ресторан, кафе, бар, столовая и др.). Источником данных послужили электронные базы словарей (academic.ru, slovari.ru, slovar.cc).

Система значений также была построена на основании определений толковых словарей. Были выделены группы значений, имеющие общий смысловой признак. Отметим, что на данном этапе в качестве дополнительного источника мы использовали межгосударственный стандарт ГОСТ 31985-2013 «Услуги общественного питания» [2], в котором дана терминологическая классификация типов ЗОП, позволяющая выявить системные характеристики смысловой структуры названий типов 3ОП. Под смысловой структурой мы понимаем те значения лингвистических знаков системы «названия типов ЗОП», которые актуализируются в тексте вывески.

К общим смысловым признакам мы отнесли: 1) питание; 2) организация досуга; 3) наличие алкоголя; 4) ассортимент. Далее было выявлено, что различные сочетания этих признаков, а также различная степень их актуализации в каждом отдельно взятом названии ЗОП вместе определяют различия между названиями 3ОП. На этом основании мы обозначили перечисленные признаки как дифференцирующие и выделили взаимосвязанные пары значений: 1) питание/досуг; 2) питание/алкоголь; 3) иирокий/ограниченный ассортимент. Признак быстрое обслуживание был классифицирован как потенциально-дифференцирующий в связи с тем, что он не имеет денотативно выраженной смысловой оппозиции (медленное обслуживание) и встречается только в классификации ГОСТ.

Приведем примеры проявления дифференцирующих признаков.

В паре питание/досуг признак досуг обнаруживается только в определениях ресторана и кафе при первостепенной актуализации признака питание (nитание + досуг).

В паре питание/алкоголь в определении ресторана первостепенным является признак питание (питание + алкоголь), а в определении бара актуализируется признак алкоголь (алкоголь + питание).

Отметим также, что в процессе построения базовой модели было выявлено, что знаки «ресторан» и «столовая» являются полярными элементами системы названий типов ЗОП по всем парам дифференцирующих признаков. Исходя из этого, в алгоритм исследования практического материала мы ввели бинар- ные оппозиции «ресторан / не ресторан» и «столовая / не столовая», которые мы использовали при анализе нетипичных случаев лингвистической репрезентации значения «тип ЗОП» в рамках вывески.

\section{Результаты исследования}

В результате лингвосемиотического анализа парадигмы «названия типов ЗОП» в практическом материале был выявлен ряд отклонений от построенной нами базовой модели как на уровне культурных кодов, так и на уровне языкового кода. Мы определили это явление как процесс формирования нового лингвокультурного кода, основные признаки которого:

1) на уровне культурных кодов - смысловые изменения в восприятии базовых (традиционных) названий типов ЗОП в общественном сознании и появление новых смыслов, не получивших пока однозначного языкового оформления;

2) на уровне языкового кода - нетипичные способы передачи значения «тип ЗОП» в тексте вывески, а также появление новых лингвистических знаков, смысловая структура которых пока окончательно не оформилась.

К нетипичным способам мы отнесли отсутствие лингвистического знака парадигмы «название типа ЗОП» (нулевой знак) в тексте вывески и присутствие более одного лингвистического знака указанной парадигмы.

В результате были выявлены 5 действующих моделей, демонстрирующих изменения в системе лингвокультурного кода, которые будут обсуждены ниже.

\section{Лингвосемиотический анализ названий типов 30П}

Названия типов ЗОП в исследованном материале представлены следующим рядом лингвистических знаков (последовательность дана в порядке убывания частотности употреблений): кафе, столовая, ресторан, бар, гастробар, паб, гастропаб, бистро, кафетерий, иашльчная, сувлачная, чебуречная, бургерная, буфет, рестобар.

Приняв описанную выше базовую модель за некую норму, при анализе лингвосемиотической системы «названия типов 3ОП» мы сфокусировали наше внимание на отклонениях от нормы как на уровне языковых знаков, так и на уровне их значений, актуализирующихся в тексте вывески.

Наиболее значительные изменения смысловой структуры традиционных лингвистических знаков парадигмы «название типа 3ОП» были обнаружены в отношении лингвистического знака «бар», который употребляется в довольно значительном количестве вывесок ЗОП (12,5 \%). Однако собственно питейным является только одно из этих заведений, в вывеске 
которого употреблен только один лингвистический знак «бар» и, соответственно, актуализировано значение «заведение, в котором пьют и едят». В остальных случаях происходит актуализация значения «организация обслуживания по типу барной стойки». На языковом уровне это является следствием сочетания знака «бар» со знаками гастрономического дискурса (далее - ГД) и/или другими знаками парадигмы «название типа ЗОП».

Рассмотрим типичную модель.

Модель 1. Изменение традиционного значения лингвистического знака «бар» при сочетании со знаком ГД связано со смещением смыслового фокуса в паре дифференцирующих признаков алкоголь + питание на питание. Например, «УСТРИЧНЫЙ БАР». Актуализация значения питание происходит под влиянием конкретизирующей информации, вводимой знаком-глюттонимом «устричный». (Здесь и далее мы пользуемся классификацией знаков гастрономического дискурса А. В. Олянича [8].) Для данной модели характерна фиксированная последовательность сочетания знаков по схеме: знак ГД + название типа ЗОП. Сочетание знаков представляет собой синтагматическое и смысловое целое, выполняющее функцию указания на тип заведения.

Поясним механизм возникновения нетипичного смысла. Информация, закодированная в сочетании знаков, соотносится с парами дифференцирующих признаков питание/алкоголь и иирокий/ограниченный ассортимент. Знак ГД вносит значение ограниченный ассортимент питания.

В результате декодируемое сообщение имеет примерно такой смысл: небольшое заведение ресторанного типа (знак «бар» исключает трактовку «столовая»), специиализиуюшееся на подаче определенного блюда, с формой обслужсиания по типу барной стойки. Отметим также, что в связи с формой обслуживания в данной модели возможно возникновение коннотации «быстрота обслуживания».

Таким образом, Модель 1 демонстрирует смену лингвокультурного кода за счет изменения смысла (культурного кода) лингвистического знака «бар» при сохранении типичного способа кодирования.

Далее рассмотрим случаи появления новых смыслов, связанные с нетипичностью языкового кода, используемого для передачи значения «тип 3ОП». 3ОП».

Нетипичные способы передачи значения «тип

Приняв за норму наличие в вывеске стандартного (общеизвестного) лингвистического знака со значением «тип 3ОП», мы выделили следующие нетипичные случаи: 1) отсутствие соответствующего лингвистического знака (нулевой знак); 2) употребление более одного лигвистического знака; 3 ) употре- бление лингвистического знака, отсутствующего в нормативной парадигме.

Отсутствие лингвистического знака «название типа 30П» обнаружено в $43 \%$ случаев. С точки зрения семиотики отсутствие лингвистического знака (нулевой знак) является значимым и, соответственно, несет определенный смысл.

В ходе анализа было установлено, что для заведений типа «столовая» употребление соответствующего линвистического знака обязательно. Следовательно, нулевой знак имеет значение «не столовая», что подразумевает «заведение ресторанного типа». При отсутствии лингвистиеского знака «название типа ЗОП» обязательная для текста вывески индексальная функция (указание на ЗОП) выполняется другими структурными элементами.

Наиболее распространенным способом передачи значения «тип ЗОП» при отсутствии лингвистического знака парадигмы «название типа ЗОП» является использование знаков гастрономического дискурса знаков-локативов, которые прямо или косвенно обозначают «место происхождения продукта или способ его приготовления» [8, с. 14].

Сравним два типичных способа указания на тип ЗОП при отсутствии в тексте вывески лингвистического знака парадигмы «название типа 3ОП» (Модели 2 и 3$)$.

Модель 2. Передача значения «тип 30П» знаком гастрономического дискурса в парадигме «дополнительная информация». Например, структура вывески «GOLD MARINA ГРУЗИНСКАЯ КУХНЯ» включает нейм (GOLD MARINA) и дополнительную информацию (ГРУЗИНСКАЯ КУХНЯ), выраженную знаком-локативом с денотативным значением «блюда грузинской кухни». Таким образом, вводится дифференцирующий признак широкий ассортимент. С учетом значения «не столовая» Модель 2 представляет собой вывеску заведения ресторанного типа (ресторан/кафе).

В связи с Моделью 2 следует отметить явление, которое мы обозначили как стирание смысловых различий между знаками «ресторан» и «кафе», так как в ряде случаев эти лингвистические знаки в вывеске соответствующего ЗОП не употребляются. Более того, анализ отзывов посетителей показал, что данные названия часто употребляются в отзывах взаимозаменяемо, а также используются для обозначения других типов ЗОП. Интересно, что аналогичную закономерность отмечают авторы исследования названий ЗОП Москвы, считающие, что «ресторан» «все чаще выступает родовым наименованием по отношению к названиям других видов заведений» [1, c. 85].

Модель 3. Передача значения «тип 3ОП» знаком гастрономического дискурса в парадигме 
«нейм». Структура вывески «Шаурма + Наггетсы» ограничивается только сочетанием знаков-локативов (названиями популярных блюд восточной и американской кухни), которые можно классифицировать как нейм в силу отсутствия других знаков.

Очевидно, что, взятые вне контекста вывески, знаки-локативы не имеют значения «тип 3ОП». Однако, будучи включенными в систему вывески, они приобретают это значение на коннотативном уровне.

Для определения типа ЗОП сравним модели по признаку ассортимент. «Кухня» как «набор блюд» в Модели 2 явно контрастирует с ограниченностью ассортимента в Модели 3. В Модели 3 значение «выбрать различные блюда» отсутствует. Следовательно, это и не заведение ресторанного типа. Для определения типа ЗОП остается только термин ГОСТа «предприятие быстрого обслуживания», «реализующее узкий ассортимент блюд, изделий, напитков несложного изготовления, как правило, из полуфабрикатов высокой степени готовности, и обеспечивающее минимальные затраты времени на обслуживание потребителей» [2]. Однако, на наш взгляд, вхождение этого термина в систему названий типов ЗОП весьма проблематично в силу следующих причин.

1. Само словосочетание «предприятие быстрого обслуживания» носит скорее описательный, а не номинативный характер.

2. Из-за своей многословности данный термин неудобен для текста вывески.

3. Вызывает сомнение и его приемлемость в повседневном общении.

В связи с использованием Модели 3 отметим также, что в текстах массовой коммуникации и в повседневном общении подобные заведения часто обозначаются словом «фаст-фуд». Однако лингвистический знак «фасm-фуд» пока также не рассматривается как элемент парадигмы «название типа ЗОП». В словарях «фаст-фуд» определяется как способ приготовления пищи, система экспресс-питания, а не тип ЗОП. В публикациях гастрономической направленности также речь идет не об отдельном типе заведения, а новом формате общественного питания, что подразумевает более одного типа заведений, объединенных по признаку «быстрое питание». Стоит также принять во внимание и негативные коннотации, ассоциируемые с фаст-фудом как с нездоровой пищей, что может помешать включению этого термина в парадигму «название типа ЗОП». Возможно, именно из-за нежелательных коннотаций в официальной типологии употребляется словосочетание «предприятие быстрого обслуживания», а не «питания».

Суммируя сказанное, можно предположить, что нулевой лингвистический знак «тип 3ОП» в системе «вывеска» является промежуточным этапом процес- са формирования нового лингвокультурного кода, связанного с появлением нового дифференцирующего признака «быстрота обслуживания». Актуализацию этого признака можно наблюдать и в отзывах посетителей. Например, «Хороший ресторанчик, все быстро и вкусно», «Еда в ичелом нормальная. Ожидание все портит».

Употребление более одного лигвистического знака «тип 3ОП» в тексте вывески также расценивается нами как отклонение от нормы, так как нарушается парадигматический принцип организации знаков в синтагме. Другими словами, затрудняется процесс декодирования значения «тип 3ОП».

Рассмотрим две типичные модели.

Модель 4. Сочетание нескольких лингвистических знаков со значением «тип 3ОП» в тексте вывески.

Для данной модели характерна следующая схема: mип $3 О П$ (отсутствует) + нейм + дополнительная информация. Например, «MANANA BAR BISTRO».

B синтагматическом пространстве подобных вывесок: 1) отсутствует лингвистический знак в парадигме «тип заведения»; 2) имеется нейм; 3) парадигма «дополнительная информация» включает последовательность знаков со значением «тип ЗОП», объединенных синтагматической связью (между знаками можно поставить союз «и»).

Таким образом, лингвистические знаки со значением «тип ЗОП» теряют функцию указания на тип заведения, а их сочетание генерирует некий новый смысл. Значение «тип заведения» в данном случае декодируется на коннотативном уровне через ассоциацию с привычным в сфере массового потребления явлением функционального многообразия продукта («два (три) в одном»).

В публикациях гастрономической направленности подобный тип ЗОП обозначается рядом слов: «фуд-корт», «фудкорт», «food court», «ресторанный дворик», - что указывает на несформированность языкового кода. Толкование этого понятия дается пока только в Викисловаре: «зона питания в торговом центре, аэропорту или, в некоторых случаях, отдельном здании, где посетителям предлагают услуги сразу несколько предприятий» [13].

В нашей выборке не обнаружено употреблений слова «фуд-корт» в парадигме «название типа ЗОП». Однако вывеска одного недавно появившегося заведения содержит указание на новый тип 3ОП на коннотативном уровне сразу в двух структурных элементах вывески: нейме и дополнительной информации: «FOOD COURT пекарня кафе бар мангал».

Подобная двойная отсылка к новому значению, во-первых, делает новое знакомым, что важно для определенной группы потребителей курортного города, впервые сталкивающихся с новым явлением. 
Во-вторых, вводятся различные благоприятные для восприятия заведения коннотации, например, «удобно», «быстро», «разнообразно», «современно».

Отметим также, что на информационно-рекламных сайтах это заведение позиционируется как ресторан. В отзывах посетителей тип данного заведения также чаще всего идентифицируется с рестораном или кафе.

Все сказанное свидетельствует о несформированности языкового кода при достаточной сформированности культурного кода в отношении Модели 4.

В следующей модели представлен еще один вариант формирования нового лингвокультурного кода: несформированность культурного кода при сформированности нового языкового кода.

Модель 5. Использование лингвистического знака со значением «название типа 3ОП», отсутствующего в нормативной парадигме, в нашей выборке представлено названиями «гастропаб», «гастробар» и «рестобар» (3\% от общего количества).

Толковые словари пока не дают определений данных слов. Определения Викисловаря отталкиваются от особенностей словообразования и акцентируют значение питание в признаке питание/алкоголь (употребляется выражение «изысканные ресторанные блюда»). При этом признаков отличия новых слов друг от друга не обнаруживается. Массовый потребитель также пока не видит особых различий между новыми типами 3ОП. Так, в отзывах о всех трех новых типах чаще всего фигурирует «ресторан», можно также встретить «гастробар» при описании гастропаба.

Таким образом, несмотря на широкое использование новых лингвистических знаков, дифференцирующие признаки, отличающие эти новые знаки от знака «ресторан», а также сами знаки друг от друга, пока отсутствуют, т. е. собственно лингвокультурный код находится в процессе формирования.

Учитывая нашу базовую модель, на данном этапе мы можем предположить, что изменения дифференцирующих признаков в первую очередь затронут пару питание/досуг и, возможно, признак ассортимент. Проанализировав ряд разножанровых интернет-источников, открывающихся по запросу «гастробар - это», мы выделили два часто встречающихся значения, ассоциируемые с новыми типами 3ОП, которые могут стать основой дифференцирующих признаков подобных ЗОП.

Значение 1: гастрономическая новизна предлагаемых блюд. Значение вводится как денотативно - словами со значением «новизна» и «необычность», - так и коннотативно - путем противопоставления с традиционным, стандартным: «без стандартных и давно приевиихся всем блюд», «мы не смогли позволить себе иметь в меню набор стандартных и давно приевшихся всем блюд» (из комментариев рестораторов).

Значение 2: атмосферность. Во многих отзывах посетителей встречается характеристика атмосферы (уютная, приятная, спокойная, дружеская и т. n.) как общего эмоционального впечатления от посещения различных типов ЗОП. Интересным является тот факт, что в связи с оценкой нового типа заведений сам лингвистический знак «атмосферный» все чаще используется как самостоятельный признак (атмосферное место), приобретая значение, ассоциируемое с комплексом новых впечатлений и позитивных эмоций.

Описанные значения свидетельствуют о том, что формирование нового культурного кода питания связано с изменением характера потребностей современного человека и повышением социальной значимости ЗОП. Нельзя не согласиться с мнением А. В. Смирнова, который считает, что современный общепит - это не просто питание «и даже не услуга, но некий процесс коммуникации, сопровождающий его приготовление и употребление» [9, с. 188].

\section{Выводы}

Обобщение наблюдений и выводов, сделанных в процессе описания результатов исследования, показало, что в лингвосемиотической системе названий типов ЗОП идет активный процесс формирования нового лингвокультурного кода как на уровне смыслов (культурных кодов), так и на уровне способов передачи новых значений парадигмы «тип ЗОП» в тексте вывесок ЗОП (языковых кодов). Выявленная динамика лингвокультурного кода представляет собой своеобразный срез изменений, происходящих в культуре общественного питания нашей страны. Особенно четко выделяются тенденции к функциональному разнообразию и к узкой гастрономической специализации. Новые значения, связанные с этими тенденциями, не получили пока однозначного языкового выражения. Несформированность языкового кода компенсируется сочетанием в тексте вывески лингвистических знаков, уже имеющихся в парадигме «названия типа ЗОП», а также использованием лингвистических знаков гастрономического дискурса. Последнее указывает на то, что новые форматы ЗОП тесно связаны с изменениями в культуре питания.

Количество новых названий типов ЗОП в исследованном материале не так велико, как, например, в Москве. Это связано, на наш взгляд, с функциональной спецификой курортного города. Сюда приезжают люди со всей страны, а как известно, типология ЗОП в регионах значительно у́же, чем в столице. И, как показало наше исследование, при сформированности языкового кода культурный код пока окончательно не 
сформировался. Поэтому, как мы считаем, перегруженность коммуникативного пространства туристической зоны новыми названиями ЗОП может создать определенный дискомфорт для ряда потенциальных потребителей.

В целом, применительно к исследованному материалу, можно с уверенностью утверждать, что выявленные языковые и смысловые изменения в системе названий типов ЗОП не только отражают современные тенденции в культуре питания, но и способствуют продвижению новых форматов общественного питания в регионы.

Подводя итог проделанной работе, надеемся, что материалы статьи могут быть полезны лингвистам, изучающим и применяющим методы лингвосемиотического анализа, а также могут быть использованы специалистами в области маркетинга и рекламы.

Следует отметить, что наблюдения и обобщения, представленные в статье, ограничены привязкой выборки к определенному месту сбора материала. Соответственно, более полную картину исследуемой парадигмы можно получить при сравнении аналогичных выборок в различных локациях $\mathrm{C}$ точки зрения авторов, перспективными направлениями дальнейших исследований являются сравнение названий типов ЗОП: 1) в различных по своей функциональной направленности туристических местах (например, приморский/горнолыжный курорт); 2) в туристических и нетуристических районах курортного города; 3) в курортном и некурортном городе.

Разработка этих направлений может внести значительный вклад в решение практических вопросов создания привлекательного образа города, а также в развитие теории рекламного дискурса.

\section{ЛИТЕРАТУРА}

1. Старикова Г. Н., Хоанг Т. Х. Ч. Трофонимы (ресторонимы) как особый тип эргонимов (на материале имен заведений общественного питания Москвы) // Вестник Том. гос. ун-та. Филология. 2017. № 47. С. 72 87.

2. ГОСТ 30389-2013. Межгосударственный стандарт / Услуги общественного питания / Предприятия общественного питания / Классификация и общие требования. Дата введения 2016-01-01. URL: https://docs.cntd. $\mathrm{ru} /$ document/1200107325

3. Брюхова О. Ю., Стариева Н. Н. Особенности нейминга в сфере общественного питания (на примере кафе города Екатеринбурга) // Филологические науки. Вопросы теории и практики. 2018. № 1-1 (79). С. 73-77.

4. Васюкова В. И., Федотовских Т. Г. Коммерческая номинация предприятий общественного питания как один из инструментов создания открытого города // Человек в мире культуры. 2016. № 1. С. 39-41.
5. Михайлюкова Н. В. Тексты вывесок как жанр рекламного дискурса (на материале языка г. Владивостока) // Филологические науки. Вопросы теории и практики. 2017. № 3-2 (69). С. 128-133.

6. Колосова Н. А. Пространство ресторана в культуре русского народа / Саратовский национальный исследовательский государственный университет имени Н. Г. Чернышевского. 2018. URL: https://www.sgu.ru/ archive/old.sgu.ru/files/nodes/9732/14.pdf

7. Смирнов A. B. Новый общепит : коммуникационная система в условиях современного города // Международный журнал исследований культуры. 2017. № 2 (27). С. 183-191.

8. Олянич A. В. Лингвосемиотика французской гастрономии : монография. Волгоград : Нива, 2015. 180 с.

9. Барт Р. Избранные труды. Семиотика. Поэтика. М. : Прогресс, 1994. 616 с.

10. Савицкий В. М. Лингвокультурные коды : к обоснованию понятия // Вестник Моск. гос. обл. ун-та. Сер.: Лингвистика. 2016. № 2. С. 55-62.

11. Давидович A. Р. Предприятия питания как основа формирования туристского пространства г. Сочи // Современные проблемы сервиса и туризма. 2014. № 2. C. $60-68$.

12. Chandler D. Semiotics for Beginners: D.I.Y. Semiotic Analysis. URL: http://www.visual-memory.co.uk/ daniel/Documents/S4B/

13. Викисловарь : многоязычный открытый словарь, международный онлайновый лексикографический проект Wiktionary. URL: https://ru.wiktionary.org/wiki/фудкорт

\section{REFERENCES}

1. Starikova G. N., Hoang T. H. Ch. Trofonimy (restoronimy) kak osobyj tip ehrgonimov (na materiale imen zavedenij obshhestvennogo pitaniya Moskvy) [Trophonyms (restoronyms) as a special type of ergonyms (on the material of Moscow eating places names)]. In: Vestnik Tomskogo gosudarstvennogo universiteta. Filologiya. 2017. No. 47. Pp. 72-87.

2. GOST 30389-2013. Mezhgosudarstvennyj standart. Uslugi obshhestvennogo pitaniya. Predpriyatiya obshhestvennogo pitaniya. Klassifikatsiya i obshhie trebovaniya [Public catering services. Enterprises of public catering. Classification and general requirements]. Data vvedeniya 2016-01-01. Available at: ttps://docs.cntd.ru/document/1200107325

3. Bryukhova O. YU., Startseva N. N. Osobennosti nejminga $v$ sfere obshhestvennogo pitaniya (na primere kafe goroda Ekaterinburga) [Peculiarities of naming in the sphere of public catering (on the example of a cafe in the city of Yekaterinburg)]. In: Filologicheskie nauki. Voprosy teorii $i$ praktiki. 2018. No. 1-1 (79). Pp. 73-77.

4. Vasyukova V. I., Fedotovskikh T. G. Kommercheskaya nominatsiya predpriyatij obshhestvennogo pitaniya kak odin iz instrumentov sozdaniya otkrytogo goroda [Commercial nomination of enterprises of public catering 
as one of the tools for creating an open city]. In: Chelovek v mire kul'tury. 2016. No. 1. Pp. 39-41.

5. Mikhajlyukova N. V. Teksty vyvesok kak zhanr reklamnogo diskursa (na materiale yazyka g. Vladivostoka) [Signboard texts as a genre of advertising discourse (on the material of the language of Vladivostok)]. In: Filologicheskie nauki. Voprosy teorii i praktiki. 2017. No. 3-2 (69). Pp. 128-133.

6. Kolosova N. A. Prostranstvo restorana v kul'ture russkogo naroda [The space of the restaurant in the culture of the Russian people]. Saratovskij natsional'nyj issledovatel'skij gosudarstvennyj universitet imeni N. G. Chernyshevskogo. 2018. Available at: https://www.sgu.ru/archive/ old.sgu.ru/files/nodes/9732/14.pdf

7. Smirnov A. V. Novyj obshhepit: kommunikatsionnaya sistema $\mathrm{v}$ usloviyakh sovremennogo goroda $[\mathrm{New}$ forms of public catering: communication system in modern cities]. In: Mezhdunarodnyj zhurnal issledovanij kul'tury. 2017. No. 2 (27). Pp. 183-191.

8. Olyanich A. V. Lingvosemiotika frantsuzskoj gastronomii [Linguosemiotics of French Gastronomy]: mono-

Сочинский институт (филиал) Российского университета дружбы народов

Рыбакова Л. В., кандидат филологических наук, доиент кафедры иностранных языков

E-mail:lvr2310@mail.ru

Сочинский государственный университет

Иванова К. П., аспирант кафедры романо-германской и русской филологии

E-mail: ksenia_ivan@list.ru

Поступила в редакцию 2 сентября 2021 г.

Принята к публикаџии 15 октября 20212.

\section{Для цитирования:}

Рыбакова Л. В., Иванова К. П. Названия типов заведений общественного питания: лингвосемиотический аспект // Вестник Воронежского государственного университета. Серия: Лингвистика и межкультурная коммуникация. 2021. № 4. C. 47-55. DOI: https://doi. org/10.17308/lic.2021.4/3810 grafiya. Volgograd: IPK Volgogradskogo GAU «Niva». 2015. 180 p.

9. Bart R. Izbrannye trudy. Semiotika. Poehtika [Selected Works. Semiotics. Poetics]. M.: Progress, 1994. 616 p.

10. Savitskij V. M. Lingvokul'turnye kody: k obosnovaniyu ponyatiya [The concept of linguocultural codes: a rationale]. In: Vestnik Moskovskogo gosudarstvennogo oblastnogo universiteta. Seriya: Lingvistika. 2016. No. 2. Pp. 55-62.

11. Davidovich A. R. Predpriyatiya pitaniya kak osnova formirovaniya turistskogo prostranstva $\mathrm{g}$. Sochi [Catering establishments as the basis for the formation of the tourist space in Sochi]. In: Sovremennye problemy servisa i turizma. 2014. No. 2. Pp. 60-68.

12. Chandler D. Semiotics for Beginners: D.I.Y. Semiotic Analysis. Available at: http://www.visual-memory.co. uk/daniel/Documents/S4B/

13. Vikislovar': mnogoyazychnyj otkrytyj slovar', mezhdunarodnyj onlajnovyj leksikograficheskij proekt Wiktionary [Wiktionary: multilingual open dictionary, international online lexicographic project]. Available at: https:// ru.wiktionary.org/wiki/фуд-корт

Sochi Institute (branch) of the Peoples' Friendship University of Russia

Rybakova L. V., Candidate of Philology, Associate Professor of the Foreign Languages Department

E-mail:lvr2310@mail.ru

Sochi State University

Ivanova K. P., Post-graduate Student of the Romano-Germanic and Russian Philology Department

E-mail: ksenia_ivan@list.ru

Received: 2 September 2021

Accepted: 15 October 2021

\section{For citation:}

Rybakova L. V., Ivanova K. P. Names of types of eating establishments: linguo-semiotic aspect. Proceedings of Voronezh State University. Series: Linguistics and Intercultural Communication. 2021. No. 4. Pp. 47-55. DOI: https:// doi.org/10.17308/lic.2021.4/3810 